\title{
Measurement of a broadband millimeter wave window for application in vacuum tubes
}

\author{
Craig R. Donaldson, Paul McElhinney, Liang Zhang, and Wenlong He \\ Department of Physics, SUPA, University of Strathclyde, Glasgow, Scotland, UK, G4 0NG
}

\begin{abstract}
This paper presents the design and measurement of a $\mathrm{HE}_{11}$ mode multilayer window that is designed for a millimeter wave broadband gyro-amplifier. The window acts to seal the vacuum inside the amplifier whilst coupling out microwave power with minimal reflection and absorption. Operating over 90-100 GHz the simulated reflection of this window is better than $-30 \mathrm{~dB}$ while the measured reflection shows a lower than $-27 \mathrm{~dB}$ reflection. The design, simulation and microwave measurement of the window is presented.
\end{abstract}

\section{INTRODUCTION}

$\mathrm{G}$ yro-amplifiers [1] which can operate over a broadband and Joutput high powers at high frequencys are in demand for applications such as dynamic nuclear polarization, electron paramagnetic resonance, high resolution radars and telecommunications. A mm-wave gyro-amplifier based on helically corrugated interaction region [2,3] and cusp electron beam source [4] is being developed in the University of Strathclyde. This source is predicted to output $\sim 5 \mathrm{~kW}$ microwave power over 90-100 GHz. There are many components in the amplifier circuit such as input coupler [5-7], Bragg reflector, polariser [8] interaction region [9], corrugated horn [10] and microwave window [11]. Each of these components is requried to have very low microwave reflection over the operating frequency range otherwise parasitic oscillations may be occured in the system. The microwave window acts to seal the amplifier from the atmosphere outside while allowing microwaves to pass through the window with minimal absorption or reflection.

Previously, a microwave window [12] based on the multilayer design has been constructed and measured to show a maximum $-20 \mathrm{~dB}$ reflection over this frequency band. That window had an input microwave mode of $\mathrm{TE}_{11}$ whilst the design in this paper is for $\mathrm{HE}_{11}$ mode. This type of microwave mode concentrates the microwave power in the centre of the waveguide so the effect of radial steps in the waveguide geometry is reduced. This property should allow both better microwave reflection, less than $-30 \mathrm{~dB}$, and make window assembly easier.

\section{WINDOW DESIGN}

Microwave windows have many variations such as the single-disc [13], multi-disc [14], pillbox [15] and Brewster [16]. The single-disc window, shown in Fig 1(a), has superior transmission over a very narrowband while the other types could operate over a broad frequency band. The Brewster window requires an plane-wave which is not directly compatible with the circularly-polarised microwave output from the helically corrugated waveguide. Therefore, in this study a multi-disc window, shown in Fig 1(b), was used due to its wider frequency bandwidth and lower reflection than pillbox window.

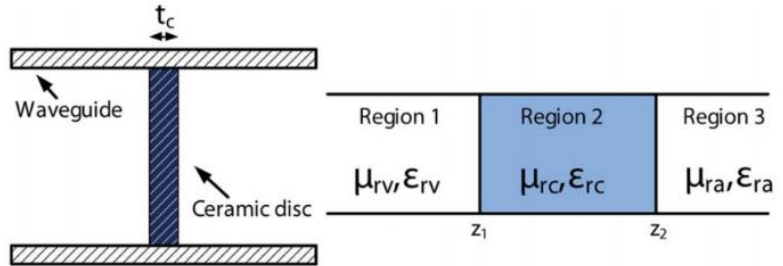

(a)

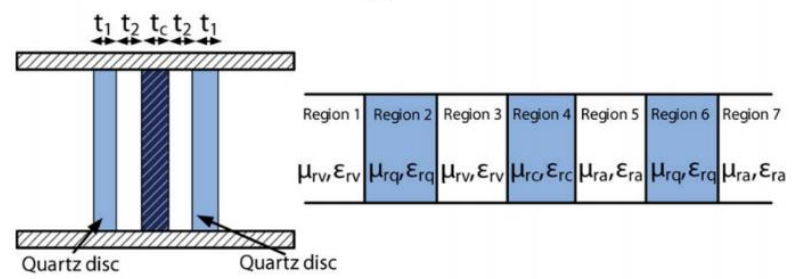

(b)

Fig. 1 Schematic diagram of the (a) single-layer microwave window and (b) multi-layer microwave window

Material choice is very important as many gyro-amplifers use a thermonic cathode which requires an ultra high vacuum free of certain elements that could poison the cathode. The ideal window materials should be also mechanically strong with a low-outgassing rate and have low microwave absoption.

\section{SIMULATION}

The multilayer window was simulated and optimised using the mode matching method with which accurate calculation of the microwave properties could be obtained in a short time. The window geometry was a central dielectric disc which was flanked by two matching dielectric discs separated by the vacuum gaps. Therefore, the window was made up of five different dielectric layers. The two matching discs are used to create additional resonant passbands on the higher and lower side of the passband generated by the central disc. Consequently, this achieves a much wider bandwidth when compared to the single disc configuration as shown in Fig 2.

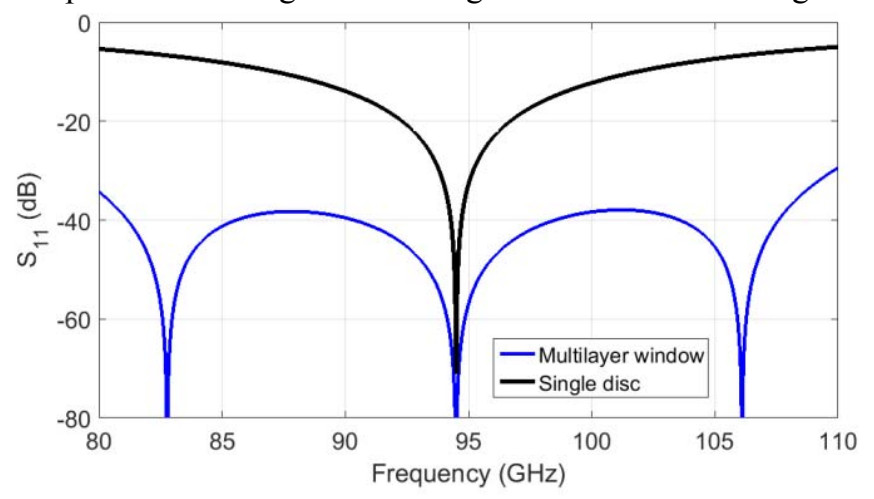

Fig. 2 Simulated ideal multilayer and single disc microwave windows. 
The central dielectric disc was Alumina $\left(\mathrm{Al}_{2} \mathrm{O}_{3}\right)$ with relative dielectric constant of 9.75. The matching discs were Quartz, with relative dielectric constant of 3.75 , as this has been shown to allow a broadband transmission whilst being compatible with the operation of the thermionic cathode. In order to create the $\mathrm{HE}_{11}$ mode input a mode converting corrugated horn [11] was used before the window. This horn converts a $\mathrm{TE}_{11}$ input mode into a $\mathrm{HE}_{11}$ output mode which has a content of approximately $85 \% \mathrm{TE}_{11}$ and $15 \% \mathrm{TM}_{11}$. In addition some higher order modes were present at the output of the horn to achieve a high coupling with a Gaussian mode.

\section{CONSTRUCTION AND MEASUREMENT}

The practical microwave window assembly had some constraints such as it had to maintain a vacuum of $10^{-9} \mathrm{mbar}$ level, as well as forming a vacuum seal with a pre-existing corrugated horn. To achieve both of these requirements the Alumina central disc was vacuum brazed into a Titanium housing which could be vacuum sealed. On both sides of the Alumina disc were Quartz discs separated by two thin copper rings to maintain the sensitive gap distances. At the air side was a copper spoke which allowed the adjustment of gap. The practice window assembly is shown in Fig. 3.

The measurement of the microwave window was made using a Vector Network Analyser (VNA). The output of this VNA was in WR10 rectangular waveguide which was then profiled to a circular waveguide. A mode converting corrugated horn was then used to convert the fundamental circular $\mathrm{TE}_{11}$ mode to the Gaussian-like $\mathrm{HE}_{11}$ mode. The multilayer window was mounted on the end of the corrugated horn, through the CF flanges. The measured microwave properties [14] showed a better than $-27 \mathrm{~dB}$ reflection which was in good agreement with the simulation results.

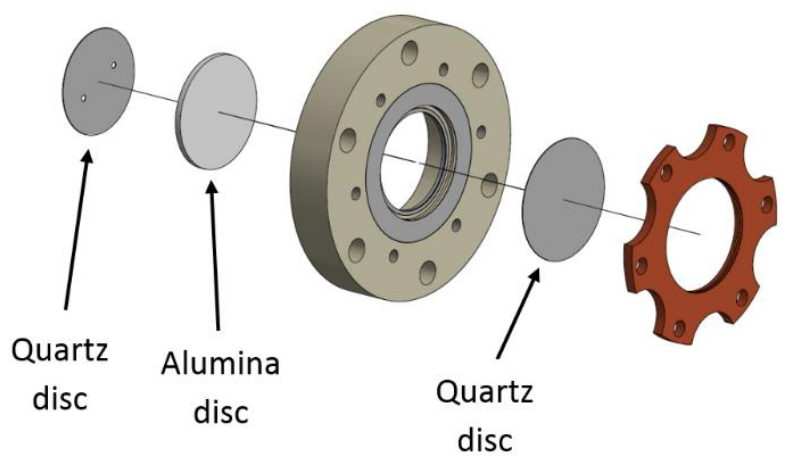

Fig. 3 Technical drawing of the multilayer window and Conflat flange.

\section{CONCLUSION}

A multilayer window was designed, simulated, constructed and measured for application in a gyro-TWA. The optimized window reflection was lower than $-30 \mathrm{~dB}$ over the frequency range of 90-100 GHz. The constructed window was vacuum tight to the required level and measured on a VNA. The measured reflection of less than $-27 \mathrm{~dB}$ was in good agreement with simulations.

\section{ACKNOWLEDGEMENTS}

The EPSRC Engineering Instrument Pool is gratefully acknowledged for providing the VNA. The authors would like to thank A. Ruddell for his assistance in setting up and installing the VNA, Dr. C. Whyte and Dr. K. Gillespie for useful discussions, as well as D. Barclay for technical assistance.

\section{REFERENCES}

[1] G. G. Denisov, V. L. Bratman, A. W. Cross, W. He, et al, "Gyrotron traveling wave amplifier with a helical interaction waveguide," Phys. Rev. Lett., vol. 81, pp. 5680-5683, Dec. 1998.

[2] W. He, C. R. Donaldson. L. Zhang, et al, "High power wideband gyrotron backward wave oscillator operating towards the terahertz region," Phys. Rev. Lett, vol. 110, 165101, Apr. 2013.

[3] A.W. Cross, W. He, A.D.R. Phelps, K. Ronald, C.G. Whyte, A.R. Young, C.W. Robertson, E.G. Rafferty, and J. Thomson, "Helically corrugated waveguide gyrotron travelling wave amplifier using a thermonic cathode electron gun," Appl. Phys. Lett. vol. 90, 253501, Jun. 2007.

[4] C.R. Donaldson, W. He, A.W. Cross, et al, "A cusp electron gun for millimeter wave gyrodevices," Appl. Phys. Lett., vol. 96, 141501, Apr. 2010.

[5] L. Zhang, W. He, C.R. Donaldson, J.R. Garner, P. McElhinney, and A.W. Cross, "Design and measurement of a broadband sidewall coupler for a W-band gyro-TWA," IEEE Trans. Microw. Theory Techn., vol. 63, pp. 31833190, Oct. 2015.

[6] J. R. Garner, L. Zhang, C. R. Donaldson, A. W. Cross, and W. He, "Design Study of a Fundamental Mode Input Coupler for a 372-GHz Gyro-TWA I: Rectangular-to-Circular Coupling Methods," IEEE Trans. Electron Devices, vol. 63, no. 1, pp. 497-503, Jan. 2016.

[7] J. R. Garner, L. Zhang, C. R. Donaldson, A. W. Cross, and W. He, " Design Study of a $372 \mathrm{GHz}$ Higher Order Mode Input Coupler", IEEE Trans. Electron Devices, accepted, 2016.

[8] L. Zhang, C.R. Donaldson, and W. He, "Design and measurement of a polarization converter based on a truncated circular waveguide," J. Phys. D: Appl. Phys., vol. 45, 345103, 2012.

[9] L. Zhang, W. He, K. Ronald, et al, "Multimode coupling wave theory for helically corrugated waveguide," IEEE Trans. Mirow. Theory Techn., vol. 60, pp. 1-7, Jan. 2012.

[10] P. McElhinney, C. R. Donaldson, L. Zhang, and W. He, "A high directivity broadband corrugated horn for W-band gyro-devices," IEEE Trans. Antennas Propag., vol. 61, 3, pp. 1453-1456, Mar. 2013.

[11] C. R. Donaldson, P. McElhinney, L. Zhang, and W. He, "Wide-band $\mathrm{HE}_{11}$ mode terahertz wave windows for gyro-amplifiers," IEEE Trans. THz Sci. Technol., vol. 6, pp. 108-112, Jan. 2016.

[12] C. R. Donaldson, W. He, L. Zhang and A. W. Cross, "A W-band multilayer microwave window for pulsed operation of gyro-devices," IEEE Microw. Wireless Compon. Lett., 3, pp. 237-239, May 2013.

[13] N. Nayek, K. Subhadra, A. Naik and S. Das, "Sapphire windows for highpower microwave and mm-wave applications," Proc. IEEE-IVEC, pp. 339-340, 2011.

[14] M-C Lin, "A multilayer waveguide window for wide-bandwidth millimeter wave tubes," Int. J. Infrared Milli. Waves., 28, pp. 355-362, 2007.

[15] N.C. Chauhan, M.V. Kartikeyan, A. Mittal, "CAD of RF windows using multiobjective particle swarm optimization," IEEE Trans. Plasma Sci., 37, pp. 1104-1109, 2009.

[16] Y. Zhang, L. Zhang, W. He, C.R. Donaldson, P. McElhinney, A.D.R. Phelps, and A.W. Cross, "Design and measurement of a W-band Brewster window," IEEE Trans. Microw Compon Lett, vol. 25, pp. 826-828, Dec. 2015. 